\title{
THE
}

1997

\section{An Empirical Eigenfunction Analysis of Sea Surface Temperatures in the Western North Atlantic}

\author{
Richard Everson \\ Peter C. Cornillon \\ University of Rhode Island, pcornillon@uri.edu \\ Lawrence Sirovich \\ Andrew Webber
}

Follow this and additional works at: https://digitalcommons.uri.edu/gsofacpubs

\section{Citation/Publisher Attribution \\ Everson, R., Cornillon, P., Sirovich, L., \& Webber, A. (1997). An Empirical Eigenfunction Analysis of Sea Surface Temperatures in the Western North Atlantic. J. Phys. Oceanogr., 27, 468-479. doi: 10.1175/ 1520-0485(1997)0272.0.CO;2.}

Available at: https://doi.org/10.1175/1520-0485(1997)027<0468:AEEAOS>2.0.C0;2

This Article is brought to you for free and open access by the Graduate School of Oceanography at DigitalCommons@URI. It has been accepted for inclusion in Graduate School of Oceanography Faculty Publications by an authorized administrator of DigitalCommons@URI. For more information, please contact digitalcommons-group@uri.edu. 


\title{
An Empirical Eigenfunction Analysis of Sea Surface Temperatures in the Western North Atlantic
}

\author{
Richard Everson, ${ }^{*}$ Peter Cornillon,${ }^{+}$Lawrence Sirovich,,$* *$ and Andrew Webber ${ }^{\#}$ \\ * Rockefeller University, New York, New York \\ + Graduate School of Oceanography, University of Rhode Island, Narragansett, Rhode Island \\ * Center for Fluid Mechanics, Brown University, Providence, Rhode Island
}

10 January 1996 and 11 July 1996

\begin{abstract}
The empirical orthogonal function decomposition is used to analyze time records of AVHRR sea surface temperature observations of the western North Atlantic from $32.9^{\circ}$ to $43.6^{\circ} \mathrm{N}, 62.7^{\circ}$ to $76.3^{\circ} \mathrm{W}$. A manually declouded dataset covering the spring of 1985 is analyzed. The majority (80\%) of the variance about the mean is accounted for by an empirical eigenfunction, which is identified with seasonal warming. This eigenfunction shows that the shelf water, excluding Georges Bank, warms the most rapidly; the surface water of the Gulf of Maine warms a little less rapidly and the Gulf Stream and Sargasso Sea surface water warm the least rapidly. The SST of the Gulf Stream is also shown to behave more like that at $30^{\circ} \mathrm{N}$ than like Sargasso Sea water immediately to its south $\left(\sim 35^{\circ} \mathrm{N}\right)$. The second EOF is found to be a small correction to the general warming rate described by the first EOF. The third and fourth EOFs are determined primarily by meander propagation. Observations with partial cloud cover from the period 1985 to 1991 are also analyzed. Again, the dominant effect is identified as seasonal warming.
\end{abstract}

\section{Introduction}

This paper presents a study of Advanced Very High Resolution Radiometer (AVHRR) sea surface temperature observations in the western North Atlantic using empirical orthogonal functions. Assimilation and interpretation of the wealth of satellite observations is a major task facing the scientist. The EOF expansion gives an optimal modal expansion of the data and permits the identification of particular modes with relevant physical processes.

This study examines a $1200 \times 1200 \mathrm{~km}^{2}$ region of the western North Atlantic from the eastern seaboard of North America to the Grand Banks and from the Sargasso Sea to Nova Scotia. The predominant contribution to sea surface temperature variability is found to be the overall seasonal warming and cooling of the ocean. A mode describing this effect is found from both a manually declouded dataset covering the spring of 1985 and also from data covering 1986-1991. The spatial form of the mode shows distinct warming rates in the Sargasso Sea, over the Grand Banks and in the shelf and slope waters. Two modes describing the meandering of the Gulf Stream are

Corresponding author address: Dr. Richard Everson, Department of Biomathematical Sciences, Mount Sinai Medical School, Box 1012, One Gustave L. Levy Place, New York, NY 10029-6574.

E-mail: rme@camelot.mssm.edu used to obtain the average phase velocity and wavelength of meanders during spring 1985.

The EOF procedure is closely related to factor analysis (Harman 1960), principal components analysis (Hotelling 1933), and singular value decomposition (Golub and Loan 1983; Moler and Morrison 1983). The technique, which has a long history (Sirovich and Everson 1992; Stewart 1993) in the guise of the Karhunen-Loève expansion (Karhunen 1947; Loève 1963), was introduced to geophysical studies by Lorenz (1956) and in recent times has found wide application in turbulence (Sirovich 1991; Berkooz et al. 1993). The snapshot method (Sirovich and Everson 1992; Sirovich 1987ac) enables the application of the technique to datasets with a great many pixels. The technique has been applied to the analysis of sea surface temperature (SST) fields obtained from both in situ observations (primarily expendable bathythermographs) and satellite-derived fields. The source of the data has in turn determined the scales, both temporal and spatial, of the analysis. Given the sparse coverage of in situ observations, EOF analyses of SST fields derived from these data have focused on large spatial and long temporal scales. Tanimoto et al. (1993) analyzed 37 years of SST anomalies in the North Pacific; Naiyou et al. (1992) considered 35 years of data for the western North Pacific; Panitz and Speth (1986) performed an EOF analysis on data for 1979 in the equatorial Atlantic; and Thompson et al. (1988) ex- 
amined 30 years of engine intake temperatures in the shelf-slope region of the northwest Atlantic. The primary focus of such studies has been large-scale atmospheric forcing and the response of the SST field as a measure of the response of the upper ocean in general.

EOF analyses of satellite-derived SST fields have tended to focus on much smaller spatial scales $(\sim 100$ $\mathrm{km})$ and temporal scales ( $\sim 100$ days): Kelly investigated the relationship between sea surface temperatures, winds, and topography over the north California slope with EOFs (Kelly 1985); Lagerloef and Bernstein have used EOFs to investigate currents in the coastal waters off California (Lagerloef 1992; Lagerloef and Bernstein 1988); Paden et al. have used the technique to investigate tidal and atmospheric forcing in the Gulf of California (Paden et al. 1991); Gallaudet and Simpson examined large-scale and mesoscale processes in the open ocean on the opposite side of the Baja Peninsula from the region considered by Paden et al. (Gallaudet and Simpson 1994); Fang and Hsieh analyzed the variability of the summer SST field off Vancouver Island with 8 years of AVHRR data (Fang and Hsieh 1993); Garzoli et al. compared EOFs derived from satellite SST fields with those derived from numerical model runs for both the Brazil/Malvinas region and the Kuroshio/Oyashio region (Garzoli et al. 1992); and Chiswell investigated the waters off New Zealand (Chiswell 1994). It is interesting to note that except for the work of Garzoli et al. (1992) and Chiswell (1994), EOF analyses of AVHRR data have been for the eastern North Pacific. To date there have been no published EOF analyses of AVHRR-derived fields for the North Atlantic despite Lagerloef and Bernstein (1988) suggestion that “... EOF analyses of remote sensing data could be directed to such strong frontal features as the Gulf Stream front. ..." The work presented herein attempts to redress this omission.

In the next section we describe the data used in this analysis and preliminary processing of these data. This is followed by a brief outline of the EOF procedure. A 120-day spline interpolated set of SST fields obtained from the AVHRR sensor is then analyzed. Data spanning several years, but with partial cloud cover, are examined in the final section of the paper.

\section{Data preparation}

\section{a. Preprocessing}

The measurements that we analyze consist of AVHRR images of the North Atlantic collected by the NOAA polar orbiting satellites. These images stretch from the eastern seaboard of North America to the Grand Banks $\left(62.7^{\circ}\right.$ to $\left.76.3^{\circ} \mathrm{W}\right)$ and from the Sargasso Sea in the south to Nova Scotia in the north $\left(32.9^{\circ}\right.$ to $\left.43.6^{\circ} \mathrm{N}\right)$. This region covers the development of the Gulf Stream and its meandering into the mid-Atlantic. Each image comprises $512 \times 512$ pixels on a rectangular grid with a pixel spacing of approximately $2.3 \mathrm{~km}$. The sea surface temperature is derived from multichannel infrared measurements. See Cornillon et al. (1987a) for details of the processing.

Cloud cover and missing data are major hindrances to the analysis of sea surface temperatures. Data may be missing from a particular image because the area of interest does not lie completely in the swath of the observing satellite. For NOAA polar orbiting satellites, this occurs approximately $12 \%$ of the time for the area of interest. Clouds are a more serious problem. A rough estimate of the cloud cover over the study area for the months March-June 1985 suggests that on average the surface is obscured $28 \%$ of the time in late spring and early summer. Taken together, these two effects result in missing data values for approximately $35 \%$ of each satellite pass. There are two ways in which these data may be analyzed with the EOF procedure: 1) the data gaps may be filled by interpolation or 2) the procedure may be modified to deal with gappy data. The first approach is undertaken here using a declouded and splineinterpolated dataset. This dataset was obtained by first manually flagging all pixels in each image thought to be contaminated by cloud cover. The remaining "clear" pixels define an irregularly spaced time series at each pixel location in the study area. For each of these locations (approximately 170000 excluding land), a continuous function of sea surface temperature in time was estimated by performing a least squares approximation to the temperature time series using cubic splines with fixed knots (de Boor and Rice 1968). A total of 17 cubic segments were used to fit the data at each location and the knots connecting these segments were fixed at the same times for all locations. A new set of images was generated by sampling each of the splines every 12 hours and then combining all interpolated values corresponding to the same times. Finally, the images were median filtered with a $7 \times 7$ pixel box. This last step tended to replace extraneous sea surface temperature values resulting from splines fit made with insufficient data. The dataset covers the spring of 1985 from 1 March to 30 June and consists of 244 images; a typical image is shown in Fig. 1. The cold continental shelf and Gulf of Maine waters show up as shades of blue in the upper half of the image. The Gulf Stream, extending from the lower left-hand corner of the image across its middle, is defined by the warmest (reddest) water, with a very sharp sea surface temperature gradient on its northern edge. To the south the slightly cooler (reddish yellow) water defines the Sargasso Sea. Between the Gulf Stream and the shelf water is the slope water (greenish yellow in the figure). The warmer approximately circular features in the shelf water are warm core rings. Two cold core rings are evident to the south of the stream. One, immediately to the east of the stream in the western part of the image, is defined by the semicircular band of warm water drawn off of the stream by the ring. The other is south of the stream on the 


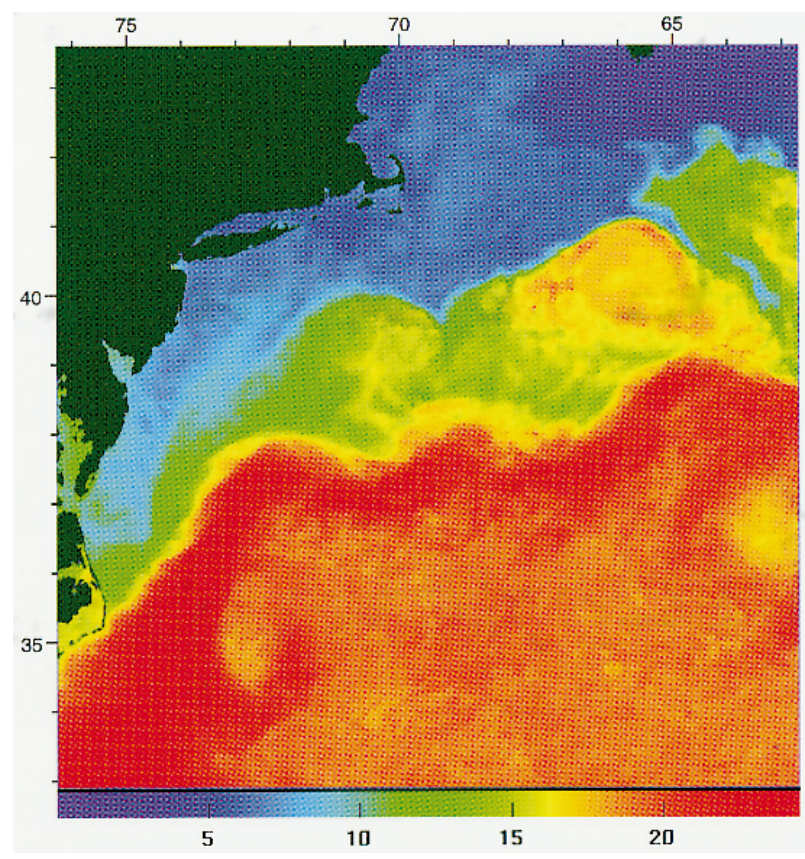

FIG. 1. AVHRR image (9 March 1985) of the western North Atlantic after spline interpolation and manual declouding. The color bar shows the temperature in Celsius and the scales at the top and left show the longitude and latitude.

eastern edge of the image and shows up as a relatively cooler near-circular region surrounded by a slightly warmer band.

\section{b. Empirical orthogonal function analysis}

We denote by $\phi(\mathbf{x}, t)$ the fluctuation, at location $\mathbf{x}$ and time $t$, of the sea surface temperature about the ensemble mean temperature, $\bar{\Phi}(\mathbf{x})=\langle\Phi(\mathbf{x}, t)\rangle$. The EOF procedure expresses the dataset of images $\left\{\Phi\left(\mathbf{x}, t_{n}\right)\right\}$ as a modal expansion:

$$
\phi(\mathbf{x}, t) \approx \sum_{n=1}^{N} a_{n}(t) \psi_{n}(\mathbf{x})
$$

The modal coefficients, $a_{n}(t)$, and the empirical orthogonal functions, $\psi_{n}(\mathbf{x})$, are determined by demanding that, for any $N$, the approximation error averaged over the entire ensemble $\left\langle\int d \mathbf{x}\left|\phi(\mathbf{x}, t)-\sum_{n=1}^{N} a_{n}(t) \psi_{n}(\mathbf{x})\right|^{2}\right\rangle$ is a minimum. The solution of this minimization problem leads to an eigenfunction equation for the EOFs ( $\mathrm{Si}$ rovich 1987a-c; Sirovich and Everson 1992).

The empirical orthogonal functions that minimize (1) form the best basis in which to represent the ensemble. The basis is intrinsic to the particular dataset because it is wholly determined by the dataset itself, hence the designation empirical.

The modal coefficients, too, are orthogonal:

$$
\left\langle a_{n}(t) a_{m}(t)\right\rangle=\lambda_{n} \delta_{n m}=\left\langle\left(\int \phi(\mathbf{x}, t) \psi_{n}(\mathbf{x}) d \mathbf{x}\right)^{2}\right\rangle .
$$

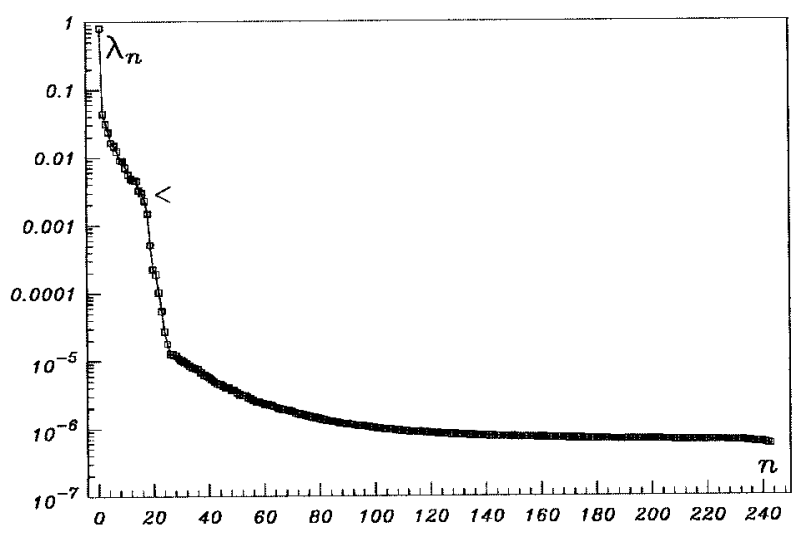

FIG. 2. Eigenvalues derived from the spline-interpolated dataset. The 17 th eigenvalue is indicated with an arrow.

The eigenvalue, $\lambda_{n}$, thus measures the mean squared projection of the data onto the $n$th empirical eigenfunction. The empirical eigenfunctions are ordered in descending order of the corresponding eigenvalues. By choosing to represent the dataset in terms of the first $N$ empirical eigenfunctions one therefore captures, on average, a fraction $\sum_{n=1}^{N} \lambda_{n} / \sum_{n=1}^{\infty} \lambda_{n}$ of the variance or energy, the maximum that can be captured using any $N$ basis functions.

\section{Results: Spline interpolated data}

We have computed the empirical eigenfunctions for the 244 manually declouded and spline interpolated sea surface temperature images. The spectrum of eigenvalues is shown in Fig. 2. The mean temperature distribution, $\bar{\Phi}(\mathbf{x})$, about which the eigenfunctions are fluctuations, is shown in Fig. 3, and the first four eigenfunctions are depicted in Fig. 4.

It is clear from the spectrum of eigenvalues that essentially all the energy in the ensemble is captured by only 17 empirical eigenfunctions. This degree of compression is an artifact however, a result of the low-pass filtering and smoothing implicit in the spline interpolation. In fact, prior to median filtering, there are only 17 degrees of freedom (corresponding to the 17 spline functions used in the interpolation) in the spline interpolated image set, and one would expect to find only 17 nonzero eigenvalues. The median filtering of the spline-interpolated images distributes some of the energy from the first 17 eigenfunctions to the remaining ones. We shall concentrate on the information provided in the first four eigenfunctions, noting that over $99 \%$ of the energy is captured by these modes.

In Table 1, the characteristics of the primary EOFs obtained in this study are compared with those of the AVHRR studies cited in the introduction. Also included in this table are the number of input images, the area covered by each image as well as the number of pixels, the period covered, and the general geographic location 


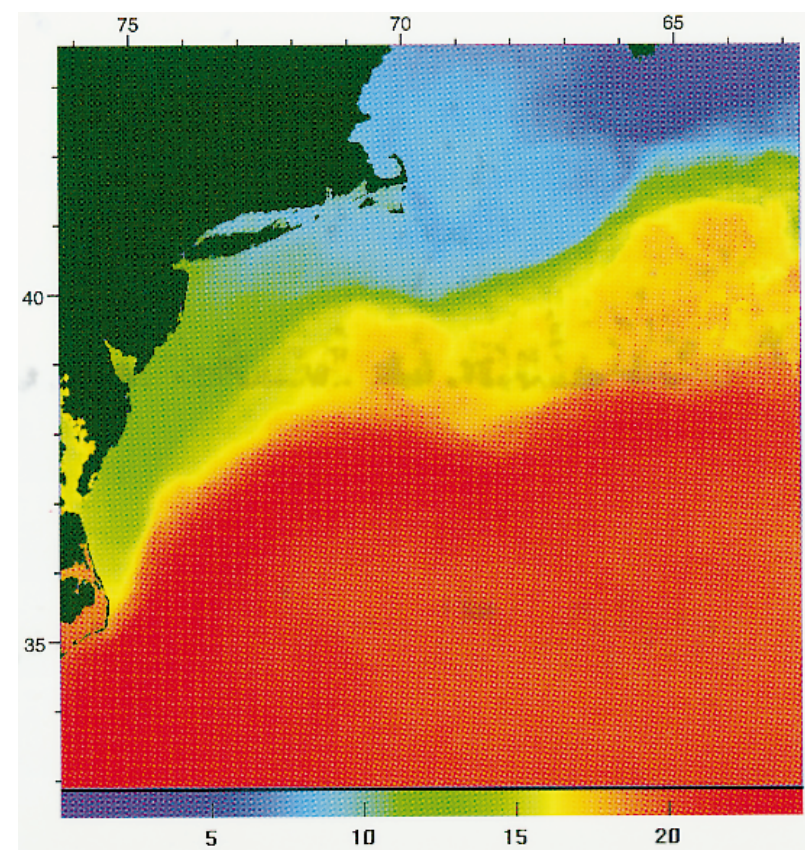

FIG. 3. Ensemble average sea surface temperature, $\Phi(\mathbf{x})$, derived from the spline-interpolated ensemble.

of the study. It is clear from the table that the fraction of variance explained by the first eigenfunction varies significantly from study to study, with the value $(80 \%)$ obtained in this study near the middle of the range. Except for the Gallaudet and Simpson (1994) results, the fraction of the variance explained by the first EOF tends to decrease with the increase in the number of temporal degrees of freedom as one would expect. Also as one might expect, the fraction of variance explained by the first EOF is much higher for semienclosed regions: the Gulf of California (Paden et al. 1991) and the Santa Barbara Channel (Lagerloef and Bernstein 1988) as compared with open ocean areas. Our results are consistent with these trends.

\section{a. Empirical eigenfunction 1}

We now examine each of the first four eigenfunctions in detail. As indicated in Table 1, on average $80 \%$ of the energy in the fluctuations is accounted for by the first eigenfunction. As can be seen in Fig. 4, $\psi_{1}(\mathbf{x})>0$ everywhere, so the eigenfunction therefore represents a warming or cooling of the entire region. The modal coefficients $a_{n}(t)$ are plotted in Fig. 5. The coefficient $a_{1}$ increases almost linearly with time, indicating a general warming with the advancing season (recall that the time series of images covers the period from March through June), and we deduce that this eigenfunction represents the seasonal warming of the sea surface. The first EOF in all of the EOF analyses performed to date on temporally demeaned AVHRR SST fields have been everywhere positive and have been associated with seasonal warming/cooling.

Temperature time series (Fig. 6, obtained from the 244 manually declouded and spline-interpolated images) for the Sargasso Sea (the location marked with an a in Fig. 4a), for the Gulf Stream (point b), for the coastal water off New Jersey (point c), and for the Gulf of Maine (point $\mathbf{d}$ ) all show a steady increase in temperature with season. The uppermost curve in this figure corresponds to the Gulf Stream (point $\mathbf{b}$ in Fig. 4a) and the least squares fit straight line to this curve has the smallest slope; that is, the increase in temperature for the Gulf Stream was smaller than that for the other three regions considered. This is consistent with the first eigenfunction (Fig. 4a) in which the Gulf Stream has the smallest values. This is not surprising given the source of Gulf Stream water. In particular, Gulf Stream surface water leaving the continental shelf at approximately $35^{\circ} \mathrm{N}$ comes from nearly equal parts of water flowing through the Florida Straits (the Florida Current) and water flowing north of the Indies (the Antilles Current), both joining the western boundary current south of $30^{\circ} \mathrm{N}$ (Cornillon 1992). Between $30^{\circ}$ and $35^{\circ} \mathrm{N}$ the western boundary current entrains less than $1 \%$ of its mass from the more seasonally variable water shoreward of the current (Stommel 1966). This, coupled with the short transit time for the surface water to move from $30^{\circ}$ to $35^{\circ} \mathrm{N}$, means that the surface water in the stream downstream of the point of separation $\left(35^{\circ} \mathrm{N}\right)$ warms at a rate closer to that at $30^{\circ} \mathrm{N}$ than at $35^{\circ} \mathrm{N}$. This is consistent with what we observe and with climatological data. Atlases of surface water properties obtained from hydrographic and from ship surface data (Weare 1977; Böhnecke 1991) show the increase between March and June in SST in the Sargasso Sea immediately to the south of the Gulf Stream $\left(\sim 35^{\circ} \mathrm{N}\right.$ between $65^{\circ}$ and $\left.70^{\circ} \mathrm{W}\right)$ to be approximately $1^{\circ} \mathrm{C}$ greater than the increase in the same longitudinal range at $30^{\circ} \mathrm{N}$. Our data (Fig. 6) show the water immediately to the south of the stream (point a in Fig. 4a) to warm by approximately $1^{\circ} \mathrm{C}$ more than water in the Gulf Stream (point $\mathbf{b}$ in Fig. 4a) over the same time interval although our data suggest warming of approximately $2^{\circ} \mathrm{C}$ less in both regions during 1985 compared with the climatological values.

The steepest curve in Fig. 6 corresponds to a point (point $\mathbf{c}$ in Fig. 4a) on the continental shelf east of the entrance to the Delaware Bay. The temperature time series at this location shows rapid warming. This is because a strong seasonal thermocline forms in the shelf water concentrating the heating to a relatively shallow surface layer when compared with the Sargasso Sea (Cornillon et al. 1987b). [Rapid warming of shelf waters compared to adjacent deep water has been observed by others (Kelly 1985; Lagerloef 1992; Gallaudet and Simpson 1994; Fang and Hsieh 1993) (although in the second mode); and (Paden et al. 1991).] The rate of warming observed here, approximately $15^{\circ} \mathrm{C}$ over the 4-month period, is similar to the climatological warming of $15^{\circ} \mathrm{C}$ observed 


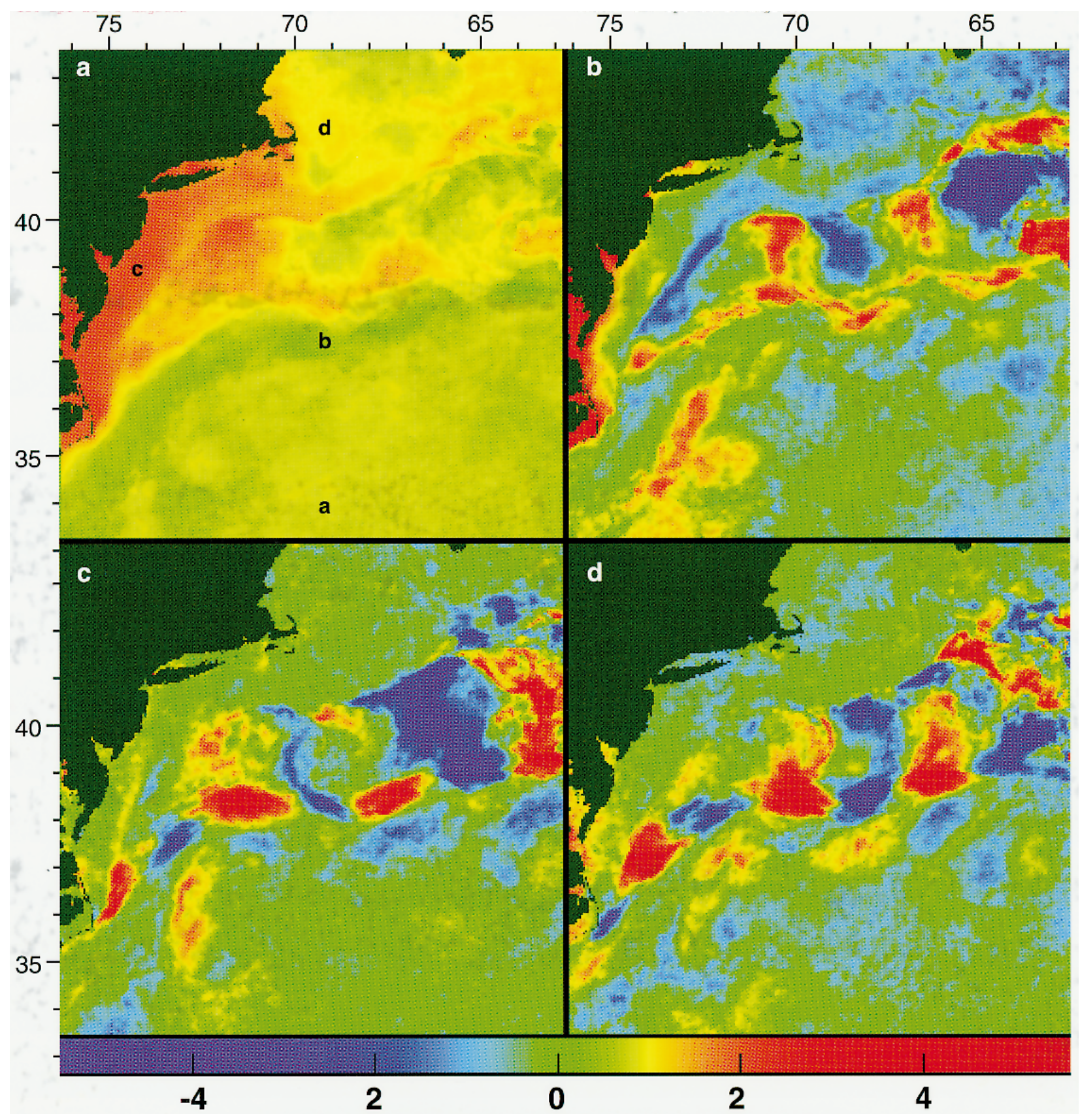

FIG. 4. First four empirical eigenfunctions derived from the spline-interpolated ensemble. Projections onto these four eigenfunctions capture $99 \%$ of the variance on average.

by Bunker (1976) for 1 April through 30 June. From Fig. 4a it is clear that this is true for all shallow water regions except for Georges Bank, point a in Fig. 4a. The difference in the water on Georges Bank results from the strong tidal mixing, which does not allow the development of a strong seasonal thermocline such as seen at other shallow water locations.

Figure $4 \mathrm{a}$ also shows that the shelf warms more rapidly on average than the slope water, although we did not attempt to quantify the change in the latter because of the significantly greater spatial variability evident in the first EOF for this water mass when compared with the four water masses represented by points $\mathbf{a}$ to $\mathbf{d}$. The large spatial variability results from the presence of warm core rings, which "drag" warm water off the Gulf Stream and cold water from the shelf as they propagate to the west (Morgan and Bishop 1977; Bisagni 1983; Garfield and Evans 1987). The more rapid warming of 
TABLE 1. Comparison of AVHRR SST EOF studies.

\begin{tabular}{|c|c|c|c|c|}
\hline & \multicolumn{4}{|c|}{ Reference } \\
\hline & Galludet 94 & Paden 91 & Kelly 85 & Fang 93 \\
\hline Location & $\begin{array}{l}\text { Southern } \\
\text { California }\end{array}$ & $\begin{array}{l}\text { Northern Gulf } \\
\text { of California }\end{array}$ & $\begin{array}{l}\text { Northern } \\
\text { California }\end{array}$ & $\begin{array}{l}\text { Vancouver } \\
\text { Island }\end{array}$ \\
\hline Size $(\mathrm{km})$ & $500 \times 500$ & $150 \times 750$ & $512 \times 512$ & $105 \times 253$ \\
\hline Number of pixels & $512 \times 512$ & $75 \times 350$ & $100 \times 100$ & $150 \times 350$ \\
\hline Period & $84-89$ & $3 / 84-2 / 86$ & $4 / 81-7 / 81$ & \\
\hline Number of images & 35 & 20 & 56 & \\
\hline First mode $(\%)$ & 38.7 & 98 & 74 & 133 \\
\hline Second mode $(\%)$ & 6.8 & 1.1 & 11 & 55.8 \\
\hline Third mode $(\%)$ & 3.9 & 0.3 & 4 & 6.9 \\
\hline Fourth mode (\%) & 3.5 & & 2 & 6.6 \\
\hline
\end{tabular}

the shelf water in comparison with the slope water is consistent with observations of Bunker (1976) and of Zheng et al. (1984). As indicated above, Bunker observed warming of $15^{\circ} \mathrm{C}$ on the shelf, while Zheng et al. observed warming of $11^{\circ} \mathrm{C}$ in the slope water for the same monthly interval.

The coldest curve in Fig. 6 corresponds to point $\mathbf{d}$ of Fig. 4a located in the Gulf of Maine off Cape Cod. The warming of $8^{\circ} \mathrm{C}$ observed here for 1 April through 30 June 1985 is identical to that observed by Bisagni and Sano (1993) from AVHRR-derived SST values for the same region but in 1987.

\section{b. Empirical eigenfunction 2}

The second eigenfunction, the most subtle of those contributing significantly, is a correction to the first eigen-
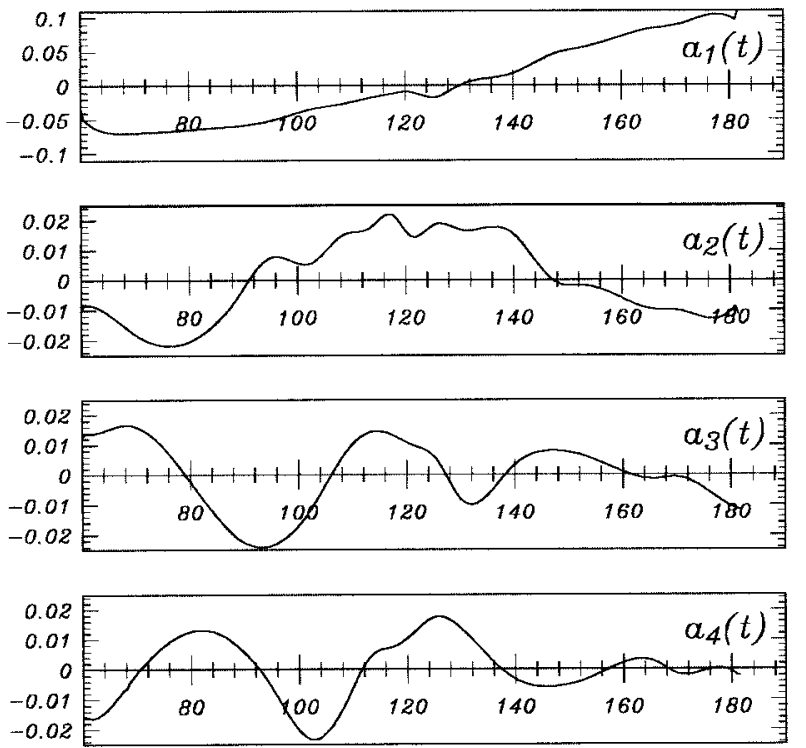

Day of Year from 1 January 1985

FIG. 5. Modal coefficients, $a_{n}(t)$, for the first four empirical eigenfunctions. The scale on the abscissa shows the day of the year 1985. The steady increase in $a_{1}$ indicates the seasonal warming of the sea surface. The coefficients, $a_{3}$ and $a_{4}$, are a quarter period out of phase, which when combined with the spatial phase shift in eigenfunctions $\psi_{3}$ and $\psi_{4}$ produces a traveling wave. function; that is, this eigenfunction provides for a slight change in the warming trend defined by the first eigenfunction. To show this, a linear trend was removed from the first modal coefficient (of the original decomposition) and a quadratic was fit to the residual signal. The residual signal (thin solid curve) and the quadratic fit (dash-dotted curve) are shown in Fig. 7 along with the second modal coefficient (dashed curve) and a quadratic fit to it (thick solid curve of negative curvature). Also shown in this figure is the quadratic fit to the second modal coefficient multiplied by -1 (thick solid curve with positive curvature). The quadratic fits to the detrended signals are almost identical in magnitude and phase, differing only in sign; hence our conclusion that the second eigenfunction is a correction to the first eigenfunction.

This correction appears to result from several different processes. These are identified by region, with the help of Fig. 8, which shows only those areas of the second eigenfunction for which its absolute value exceeds 0.025, that is, only those areas contributing significantly to the

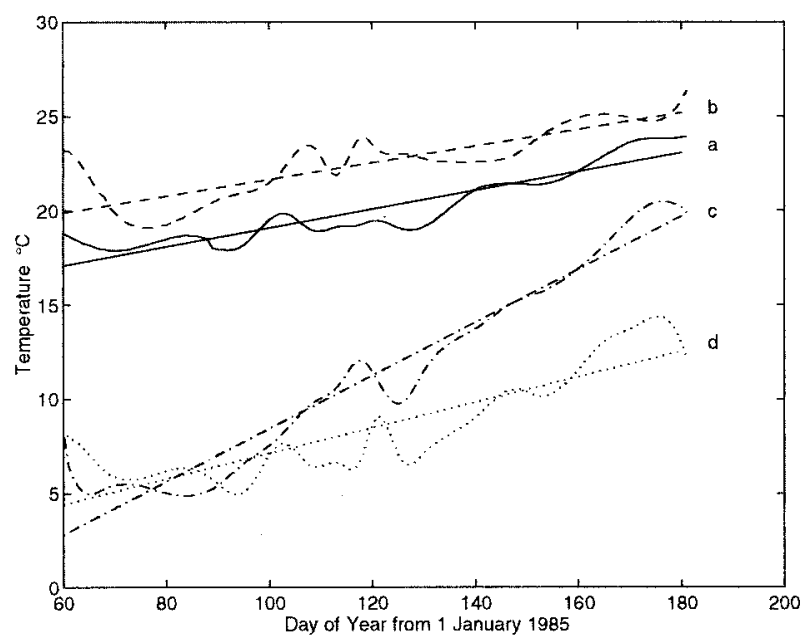

FIG. 6. Temperature as a function of time averaged over 11.5 by $11.5 \mathrm{~km}^{2}$ areas $\left(5 \times 5\right.$ pixels) centered on $\left(34^{\circ} \mathrm{N}, 69^{\circ} \mathrm{W}\right)$ (solid); $\left(37.5^{\circ} \mathrm{N}, 69^{\circ} \mathrm{W}\right)$ (dashed); $\left(42^{\circ} \mathrm{N}, 69^{\circ} \mathrm{W}\right)$ (dotted); and $\left(39^{\circ} \mathrm{N}, 74^{\circ} \mathrm{W}\right)$ (dash-dotted). Also indicated are the best fit, in a least square sense, straight lines. The letters next to the curves correspond to the points labeled in Fig. 4a. 
TABLE 1. (Extended)

\begin{tabular}{|c|c|c|c|c|}
\hline \multicolumn{5}{|c|}{ Reference } \\
\hline Lagerloef 88 & Garzoli 92 & Garzoli 92 & This study & This study \\
\hline $\begin{array}{l}\text { Santa Barbara } \\
\text { Channel }\end{array}$ & $\begin{array}{l}\text { Brazil/Malvinas } \\
\text { Current }\end{array}$ & $\begin{array}{l}\text { Kuroshio/Oyashio } \\
\text { Current }\end{array}$ & Gulf Stream & Gulf Stream \\
\hline $50 \times 100$ & $512 \times 512$ & $512 \times 512$ & $1200 \times 1200$ & $1200 \times 1200$ \\
\hline $50 \times 100$ & $15 \times 15$ & $20 \times 30$ & $512 \times 512$ & $512 \times 512$ \\
\hline \multirow[t]{2}{*}{$1 / 84-1 / 85$} & $7 / 84-7 / 88$ & $11 / 81-12 / 89$ & $3 / 85-7 / 85$ & $86-91$ \\
\hline & & & 244 & 73 \\
\hline 36 & 263 & 434 & 80 & 62 \\
\hline 91.6 & 85.7 & 84.6 & 4.4 & 3.4 \\
\hline \multirow[t]{2}{*}{2.5} & 2.7 & 5.5 & 3.1 & 2.7 \\
\hline & 1.5 & 1.5 & 2.3 & 1.9 \\
\hline
\end{tabular}

correction. Values from -0.025 to 0.025 are colored gray in the figure. Superimposed on the second eigenfunction in this figure are the continental outline in red, the 200-m isobath in white, and, crosshatched in black, regions of persistently high SST gradient. The persistent gradient regions were obtained by applying a Sobel gradient operator (Duda and Hart 1973) to each of the images in the time series, averaging the resulting gradient images and then marking locations in the figure where this average exceeded a given threshold.

The different areas contributing significantly to the correction term are 1) a narrow band (yellow) hugging the coast that extends south from the mouth of the Delaware Bay $\left(\sim 39^{\circ} \mathrm{N}\right)$ to Cape Hatteras $\left.\left(\sim 35^{\circ} \mathrm{N}\right), 2\right)$ a moderately large region (yellow) seaward of the southern edge of the Gulf Stream off Cape Hatteras, 3) a band (yellow) that follows the northern edge of the Gulf Stream, 4) a band (blue/green) that follows the 200-m isobath from approximately the entrance of Chesapeake Bay $\left(\sim 37^{\circ} \mathrm{N}\right)$ to the middle of Georges Bank $\left(\sim 67^{\circ} \mathrm{W}\right)$ and along most of the extent of this isobath in the Gulf of Maine, and 5) alternating bands (yellow and blue/

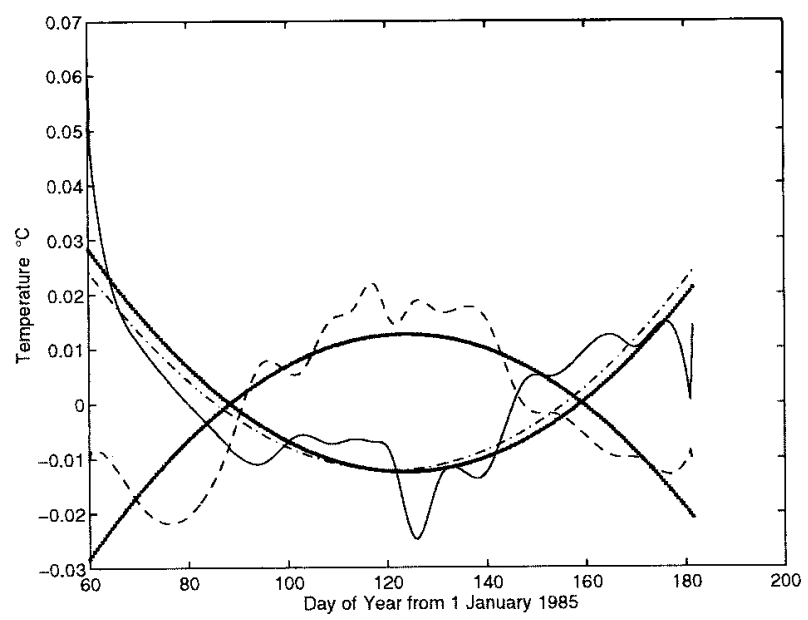

FIG. 7. Coefficient of the first EOF after removing a linear trend (thin solid). Least square fit quadratic to the residual of the first EOF (dash-dot). Second EOF (dash). Least square fit quadratic to the second EOF (bold) and the negative of this fit (bold). green/violet) between regions 3 and 4 . The processes involved in the correction differ from one area to another. The correction due to region 1 clearly results from coastal runoff from the Delaware and the Chesapeake Bays (Ketchum and Keen 1955; Wright and Parker 1976). The region becomes wider to the south both because the Chesapeake adds to the runoff and because the plume is mixed to greater distances off shore as it moves to the south. The modification here results in more rapid warming early in the period. This occurs because the shallow, fresher water in the Delaware Bay and the Chesapeake Bay is warmed more rapidly than the shelf water. Fig. 9a shows the contribution to the temperature at $\left(36.9^{\circ} \mathrm{N}, 75.8^{\circ} \mathrm{W}\right)$, the mouth of the Chesapeake Bay, as a function of time for the first EOF (thin) and for the sum of the first two EOFs (bold).

Regions 2 and 5 are related to rapid changes in SST caused by warm water being advected off the Gulf Stream by a cold core ring for region 2 and by two warm core rings for region 5. Early in the time series the cold core ring-stream interaction is clearly visible (not shown here) as a thin band of Gulf Stream water being drawn off of the stream as the ring begins to interact with the it. Toward the middle of the interval the ring-stream interaction is much more vigorous and large quantities of water are drawn off of the stream into the adjacent Sargasso Sea. The interaction between the stream and the warm core rings occurs as large eastward propagating meanders touch the rings again drawing off warm Gulf Stream water.

The remaining regions, 3 and 4, are, we believe, associated with vertical motion or mixing in the water column, which tends to modify the warming rate when compared to regions with relatively little vertical motion. An alternative hypothesis is that regions 3 and 4 in this EOF result from the simple horizontal displacement of strong fronts during the course of the study. We discount this hypothesis, however, because the bands in regions 3 and 4 are offset relative to the bands containing the persistent fronts (Fig. 8) and because motion of the fronts would require another EOF in quadrature with this one and none is apparent. Large vertical motion, on the other hand, can result in a temporal change in the SST that may be ex- 


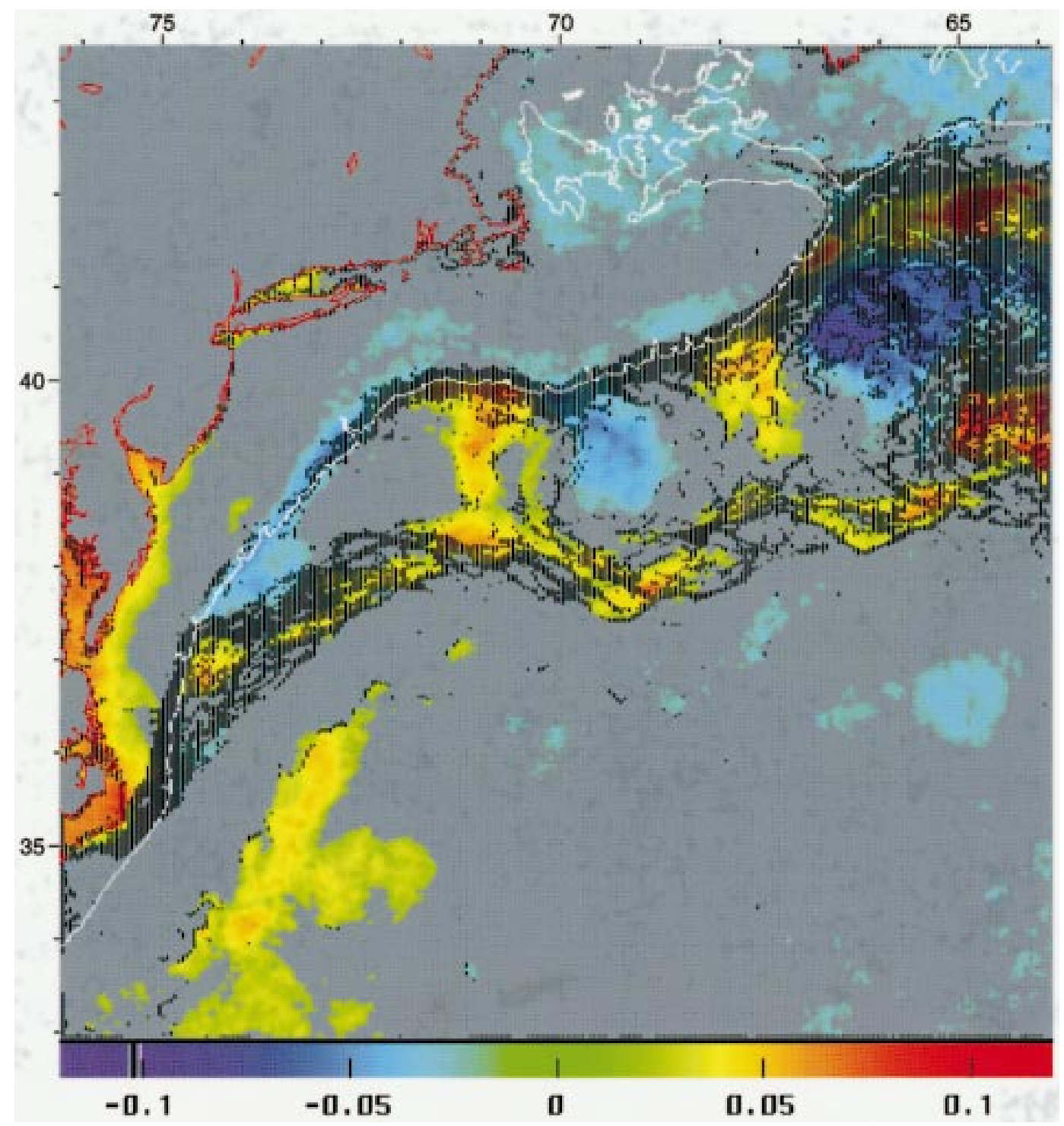

FIG. 8. Second EOF with regions of magnitude less that 0.025 masked (gray), 200-m isobath (white), continental outline (red), persistent fronts (crosshatched in black).

plained by one EOF. Such motion is often related to strong fronts associated with steep gradients in bathymetry (the shelf break near the 200-m isobath) (Voorhis et al. 1976; Houghton and Marra 1983; Houghton et al. 1988) and steep gradients in dynamic topography (the northern edge of the Gulf Stream) (Bower et al. 1985; Bower and Rossby 1989; Meyers 1994). The relationship between the second EOF and persistent fronts associated with bathymetry (region 3) and persistent fronts associated with the northern edge of the Gulf Stream (region 4) is presented in Fig. 8.

Figure $9 \mathrm{~b}$ shows the time series of the first EOF (thin) and the sum of the first two EOFs (dash-dot) for a location in the shelf/slope front band $\left(39.3^{\circ} \mathrm{N}, 72.6^{\circ} \mathrm{W}\right)$ and the sum of the first two EOFs (bold) for a location in the Gulf Stream frontal band $\left(38.3^{\circ} \mathrm{N}, 70.6^{\circ} \mathrm{W}\right)$. The first EOF at the Gulf Stream location is almost identical to that at the shelf/slope front hence is not shown. The correction of the second EOF provides for more rapid warming in the shelf/slope frontal band early in the time series and less rapid warming later in the time series. The correction for the band along the northern edge of the Gulf Stream is of opposite sign but approximately of the same magnitude.

Given that several different processes contribute to the second EOF, the question naturally arises as to whether or not some dominate. In particular, are the features associated with the possibly more interesting processes such as vertical motion in the vicinity of strong fronts robust? In order to demonstrate that the two bands in the 

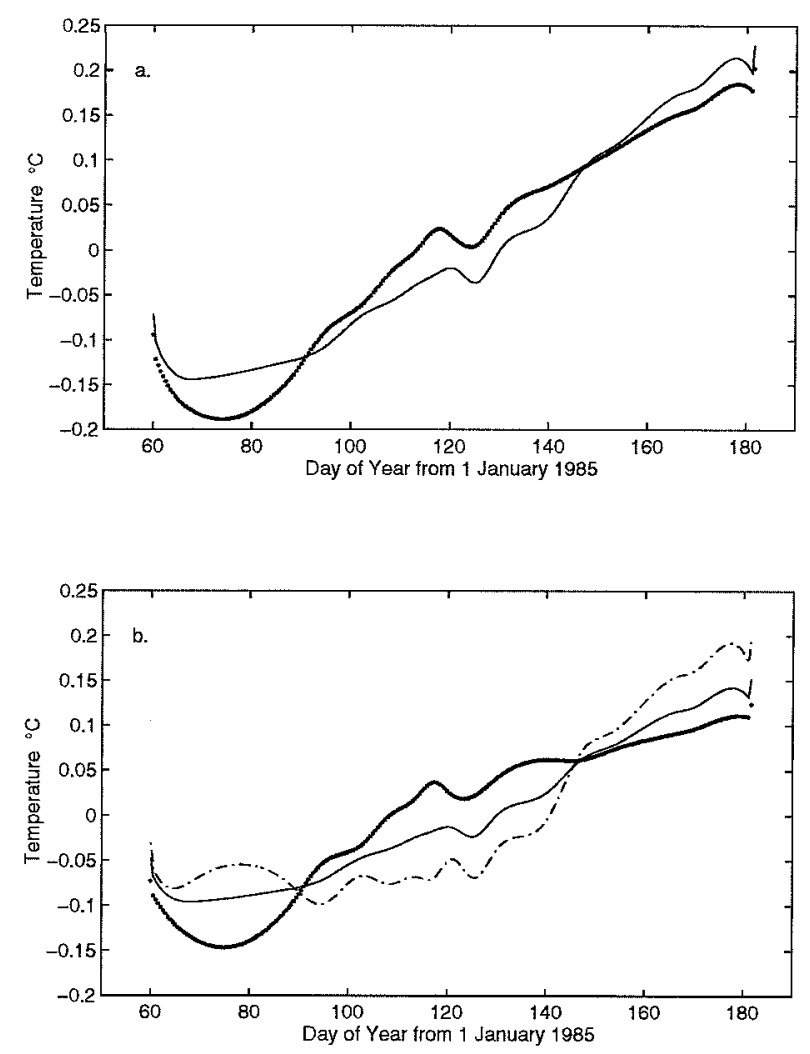

FIG. 9. (a) Time series of the first EOF (thin solid) and the sum of the first two EOFs (bold) at the entrance to the Chesapeake Bay $\left(36.9^{\circ} \mathrm{N}, 75.8^{\circ} \mathrm{W}\right)$. (b) Time series of the first EOF (thin solid) and of the sum of the first two EOFs (bold) along the northern edge of the Gulf Stream $\left(38.3^{\circ} \mathrm{N}, 70.6^{\circ} \mathrm{W}\right)$ and of the sum of the first two EOFs (dash-dot) in the shelf/slope frontal band $\left(39.3^{\circ} \mathrm{N}, 72.6^{\circ} \mathrm{W}\right)$.

second eigenfunction associated with persistent fronts (regions 3 and 4) constitute a significant contribution to this mode, the Sargasso Sea, the slope water region, the continental shelf, and the Gulf of Maine were covered with a mask and the EOF procedure was applied to the resulting time series of images. The first four eigenfunctions obtained are shown in Fig. 10 and the modal coefficients in Fig. 11. The first eigenfunction again corresponds to a general seasonal warming, the second and third to propagating meanders (discussed below), and the fourth to the previous second mode. Aside from a reordering of the eigenfunctions and a slight change in the shape of the eigenfunctions and their modal coefficients, the information content is largely the same as obtained from the unmasked time series; the signal associated with the two isolated bands is robust.

\section{c. Empirical eigenfunctions 3 and 4}

The third and fourth eigenfunctions (Figs. $4 \mathrm{c}$ and $4 \mathrm{~d}$ ) are large only in the Gulf Stream and slope water regions. In the Gulf Stream region they have the approximate form of a pair of modes that are $\pi / 2$ out of (spatial) phase with each other. This is particularly ev- ident in Fig. 10 (modes 2 and 3 in this case). The corresponding modal coefficients (Fig. 5) are roughly sinusoidal oscillations one-quarter period out of phase with each other. It can be seen that the period is approximately 40 days. The superposition

$$
a_{3}(t) \psi_{3}(\mathbf{x})+a_{4}(t) \psi_{4}(\mathbf{x})
$$

is thus approximately a traveling wave, representing the meandering of the Gulf Stream. The 40-day period agrees well with that of the most energetic meanders (46 days) obtained by Lee and Cornillon (1996) from an analysis of eight years of satellite-derived Gulf Stream paths. The wavelength of these meanders, measured from either the third or fourth eigenfunction, 375 $\mathrm{km}$, is comparable to that obtained by Lee and Cornillon, $427 \mathrm{~km}$, and can be regarded as the representative scale of a traveling wave. From the period and wavelength we estimate the phase velocity as $9.4 \mathrm{~cm} \mathrm{~s}^{-1}$, a little smaller than the mean phase speed of $\sim 12 \mathrm{~cm} \mathrm{~s}^{-1}$ observed by Lee and Cornillon (1996).

\section{Results: Partial data}

We have also examined an ensemble of 73 fairly cloudless and complete images. This ensemble covers approximately the same region as the previous ensemble but was obtained by searching several thousand images from 1986 to 1991 to find those with putatively less than $10 \%$ cloud cover or missing regions. Nonetheless, these images are flawed by missing pixels and cloud cover. The EOF procedure was therefore modified to cope with these flaws (Everson and Sirovich 1995).

The spectrum of eigenvalues for the relatively cloudfree ensemble is less compact than for the declouded, smoothed and interpolated ensemble. That a greater number of eigenfunctions contribute significantly may be attributed to two facts: 1) the data now record sea surface temperatures in four seasons over a number of years, rather than a single season and 2) as noted previously, the process of fitting a spline to the declouded dataset constrains the number of degrees of freedom. Even so, for the multiyear dataset, only 32 modes are required to capture $90 \%$ of the energy and we estimate that modes with indices greater than about 20 are dominated by noise. The first four EOFs account for approximately $70 \%$ of the variance (Table 1).

The first empirical eigenfunction, which has approximately the same form as Fig. 4a, carries the bulk of the variance $(62 \%)$. The large change in variance between eigenvalues 1 and 2 is a feature in common with other studies (see Table 1) and indicates that the sea surface temperature is dominated by seasonal warming and cooling. The fact that the form of this eigenfunction is quite similar to that of the first eigenfunction derived from the spline-interpolated data supports the idea that this EOF represents the gross seasonal warming and cooling of the ocean.

The modal coefficient corresponding to this EOF was 


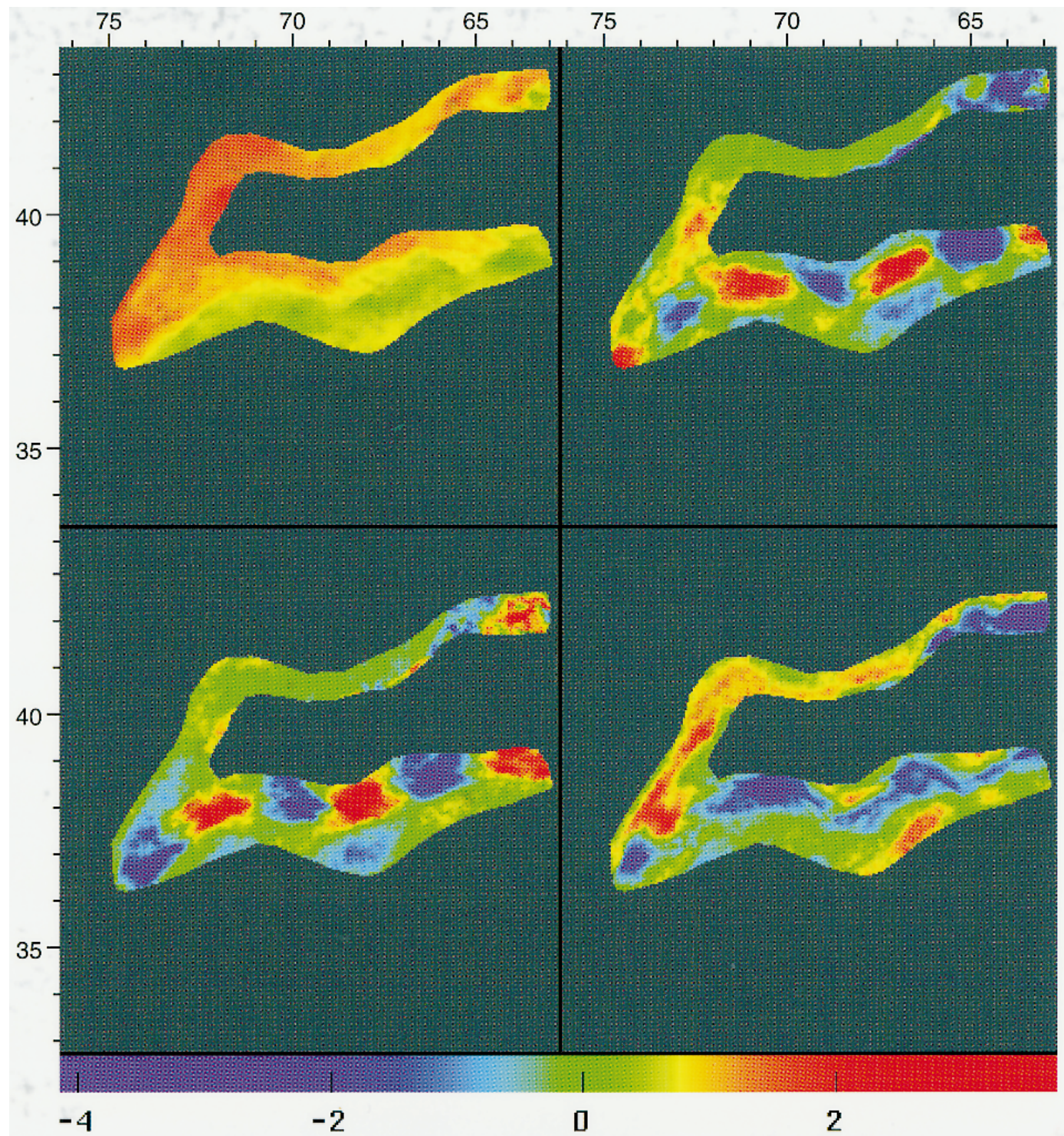

FIG. 10. First four EOFs found in the regions associated with persistent fronts.

estimated by a least squares procedure (Kelly 1985; Everson and Sirovich 1995) from the unflawed observations [i.e., excluding missing pixels, those colder than the mean $\bar{\Phi}(\mathbf{x})$ by $5^{\circ} \mathrm{C}$, and those colder than $\left.0.5^{\circ} \mathrm{C}\right]$. Figure 12 shows the coefficient as estimated from the ensemble of 73 snapshots spanning 1986-1991 and used to find the eigenfunctions. Choosing relatively unobscured snapshots means that a large proportion of data comes from the months of July and August, when the skies are clear; this clustering of the data is obvious in the figure. Although the data are irregularly spaced, the interpretation of the first eigenfunction as a mode describing the seasonal warming is compelling.

In Fig. 13 the coefficient of seasonal warming for a single year (54 snapshots at roughly weekly intervals throughout 1990) is shown. Each data point is derived from a single snapshot and the eigenfunctions from the relatively cloud-free ensemble. The annual warming and cooling cycle, peaking in August, is apparent.

Empirical eigenfunctions corresponding to the meandering of the Gulf Stream are now not evident. This is not surprising both because the average separation in time between images is approximately 30 days, close to the period of the dominant meanders, and because the stream moves laterally from year to year (Lee and Cornillon 1995).

\section{Summary}

In the preceding we analyzed, using the EOF procedure, a series of sea surface temperature images covering the Gulf Stream and surrounding ocean from the 

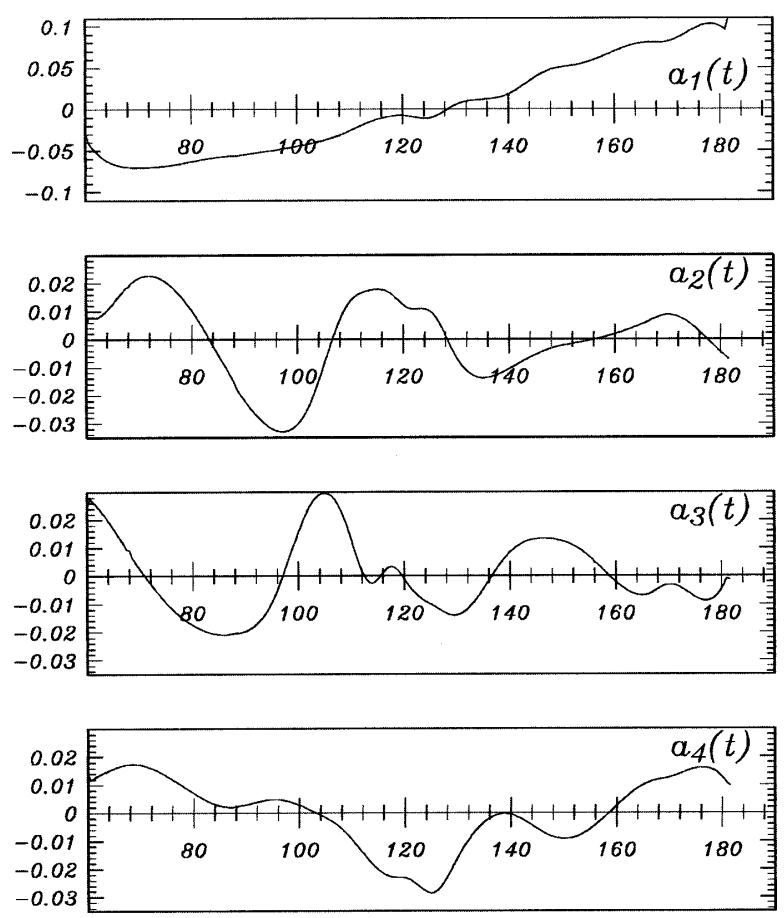

Day of Year from 1 January 1985

FIG. 11. Modal coefficients $a_{n}(t)$ for EOFs in the regions associated with persistent fronts.

point of separation (off Cape Hatteras), $\sim 75^{\circ} \mathrm{W}$, to the New England Seamounts, $\sim 65^{\circ} \mathrm{W}$. These images were spatially complete, clouds having been replaced by an interpolated value obtained from cubic splines fit at each pixel location. The first mode, explaining $80 \%$ of the variance, was shown to correspond to seasonal heating/ cooling. This is typical of the results of other EOF analyses as is the fraction of the variance explained by this mode. Also consistent with previous analyses, waters on the continental shelf were shown to heat up more quickly than those in the open ocean as spring progresses into summer. Less typical are the different rates of warming seen in the open ocean. Unlike other results obtained from EOF analyses, the next three higher order EOFs were shown to correspond to a subtle correction to the first mode and to propagating meanders. The average phase velocity and wavelength of the meanders was obtained from the EOFs.

The technique was also applied to a number of images covering several years. These images were not spatially complete, so the EOF procedure had to be modified to handle gappy data. In this case the first mode explained only $60 \%$ of the variance and the higher order modes could not be associated with propagating meanders. These results are not surprising, since in the longer time series the images used were too far apart in time for a given meander to appear in more than one or two, and the irregular temporal spacing of the images did not allow for propagating meanders to be followed.

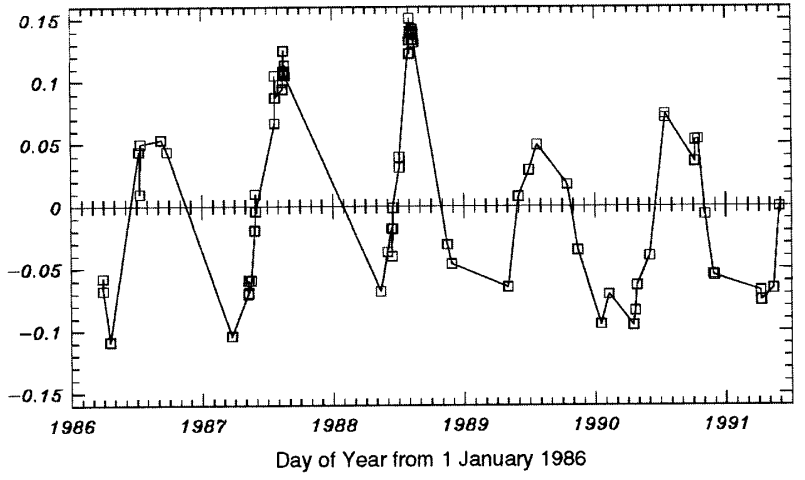

FIG. 12. The coefficient of the first empirical eigenfunction estimated from the clear regions of snapshots drawn from the years 198691. Though the data are irregularly spaced (and missing in the cloudy spring months) the annual cycle of seasonal warming is apparent.

Acknowledgments. This paper was prepared with support from the Office of Naval Research, the Naval Research Laboratory, Stennis Space Center (N00014-931-G901); from the National Aeronautics and Space Administration (NAGW 3009); and from the State of Rhode Island and Providence Plantations through salary support to P. Cornillon. The satellite data processing software used to process the imagery was developed by R. Evans, O. Brown, J. Brown, and A. Li of the University of Miami. Their continued support is greatly appreciated. The comments of two anonymous reviewers as well as those of Gary Lagerloef have also helped to improve this manuscript substantially. Their effort in this regard is appreciated.

\section{REFERENCES}

Berkooz, G., P. Holmes, and J. Lumley, 1993: The proper orthogonal decomposition in the analysis of turbulent flows. Аппи. Rev. Fluid Mech., 25, 539-575.

Bisagni, J. J., 1983: Lagrangian current measurements within the

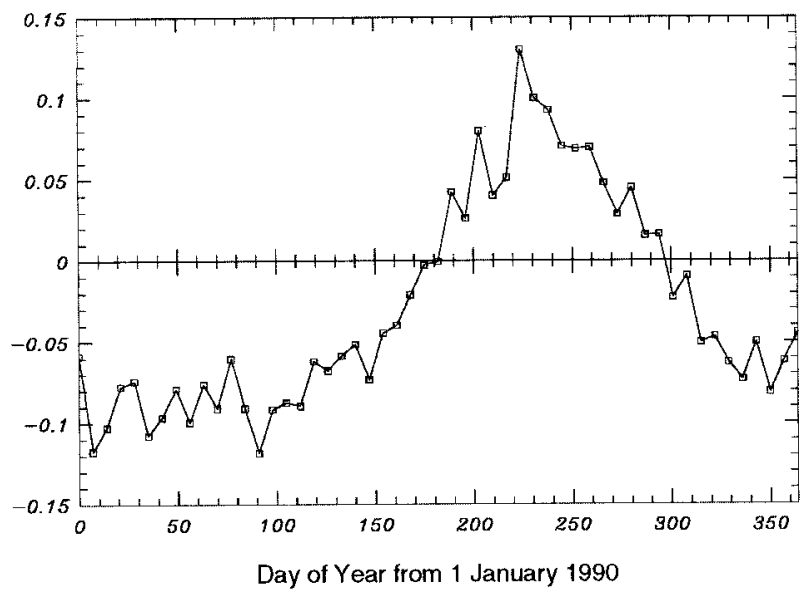

FIG. 13. The coefficient of the first empirical eigenfunction estimated from weekly snapshots in 1990 . 
eastern margin of a warm-core Gulf Stream ring. J. Phys. Oceanogr., 13, 709-715.

— temperature variability on southern Georges Bank. Contin. Shelf Res., 13, 1045-1064.

Böhnecke, G., 1991: Temperature, Salinity and Density of the Surface Waters of the Atlantic Ocean. Amerind, $97 \mathrm{pp}$.

Bower, A. S., and H. T. Rossby, 1989: Evidence of cross-frontal exchange processes in the Gulf Stream based on isopycnal RAFOS float data. J. Phys. Oceanogr., 19, 1177-1190.

,-- , and J. L. Lillibridge, 1985: The Gulf Stream-Barrier or blender? J. Phys. Oceanogr., 15, 24-32.

Bunker, A. F., 1976: Computations of surface energy flux and annual air-sea interaction cycles of the North Atlantic Ocean. Mon. Wea. Rev., 104, 1122-1140.

Chiswell, S., 1994: Variability in sea surface temperature around New Zealand from AVHRR images. N. Z. J. Mar. Freshwater Res. 28, 179-192.

Cornillon, P., 1992: Gulf Stream. Encyclopedia of Earth System Science, Vol. 2, Academic Press, 465-480.

- C. Gilman, L. Stramma, O. Brown, R. Evans, and J. Brown, 1987a: Processing and analysis of large volumes of satellite derived data. J. Geophys. Res., 92, 12 993-13 002.

— L. Ltramma, and J. F. Price, 1987b: Satellite measurements of sea surface cooling during Hurricane Gloria. Nature, 326, 373 375.

de Boor, C., and J. Rice, 1968: Cubic spline approximation I-fixed knots. Computer Science Department Tech. Rep., Purdue University, 392 pp. [Available from Purdue University, West Lafayette, IN 47907.]

Duda, R., and P. Hart, 1973: Pattern Classification and Scene Analysis. Wiley and Sons, $482 \mathrm{pp}$.

Everson, R., and L. Sirovich, 1995: The Karhunen-Loève transform for incomplete data. J. Opt. Soc. Amer., Ser. A 12(8), $1657-$ 1664 .

Fang, W., and W. Hsieh, 1993: Summer sea surface temperature variability off Vancouver Island from satellite data. J. Geophys. Res., 98, 14 391-14 400.

Gallaudet, T. C., and J. J. Simpson, 1994: An empirical orthogonal function analysis of remotely sensed sea surface temperature variability and its relation to interior oceanic processes off Baja California. Remote Sens. Environ., 47, 375-389.

Garfield, N., and D. L. Evans, 1987: Shelf water entrainment by Gulf Stream warm-core rings. J. Geophys. Res., 92, 13 003-13 012.

Garzoli, S. L., Z. Garraffo, G. Podesta, and O. Brown, 1992: Analysis of a general circulation model product 1 . Frontal systems in the Brazil/Malvinas and Kurshio/Oyashio regions. J. Geophys. Res., 97, $20117-20138$.

Golub, G., and C. V. Loan, 1983: Matrix Computations. North Oxford Academic, $642 \mathrm{pp}$

Harman, H., 1960: Modern Factor Analysis. University of Chicago Press, $469 \mathrm{pp}$

Hotelling, H., 1933: Analysis of complex statistical variables in principal components. J. Educ. Psy., 24, 417-441, 498-520.

Houghton, R. W., and J. Marra, 1983: Physical/biological structure and exchange across the thermohaline shelf/slope front in the New York Bight. J. Geophys. Res., 88, 4467-4481.

_ F. Aikman III, and H. W. Ou, 1988: Shelf-slope frontal structure and cross-shelf exchange at the New England shelf-break. Contin. Shelf Res., 8, 687-710.

Karhunen, K., 1947: Uber lineare methoden in der wahrscheinlichkeitsrechnung. Amer. Ann. Acad. Sci., Fennicade, Ser. A, 37, $3-79$.

Kelly, K., 1985: The influence of winds and topography on sea surface temperature patterns over the northern California slope. J. Geophys. Res., 90, $11783-11798$.

Ketchum, B. H., and D. J. Keen, 1955: The accumulation of river water over the contintenal shelf between Cape Cod and Chesapeake Bay. Deep-Sea Res., 3, 346-357.

Lagerloef, G., 1992: The Point Arena Eddy: A recurring summer anticyclone in the California Current. J. Geophys. Res., 97, 12 557-12 568

— of Advanced Very High Resolution Radiometer surface temperature patterns in the Santa Barbara Channel. J. Geophys. Res., 93, 6863-6873.

Lee, T., and P. Cornillon, 1995: Temporal variation of meandering intensity and domain-wide lateral oscillation of the Gulf Stream. J. Geophys. Res., 100, 13 603-13 613.

$\longrightarrow$, and -1996 : Propagation of Gulf Stream meanders between $74^{\circ}$ and $70^{\circ}$ W. J. Phys. Oceanogr., 26, 205-224.

Loève, M., 1963: Probability Theory. 3d ed. Van Nostrand, 685 pp. Lorenz, E., 1956: Empirical orthogonal functions and statistical weather prediction. Tech. Rep. 1, Statistical Forecasting Project, Department of Meteorology, Massachusetts Institute of Technology, Cambridge, Massachusetts, $49 \mathrm{pp}$.

Meyers, S. D., 1994: Cross-frontal mixing in a meandering jet. $J$. Phys. Oceanogr., 24, 1641-1646.

Moler, C., and D. Morrison, 1983: Singular value analysis of cryptograms. Mem. Amer. Math. Soc., 90, 78-87.

Morgan, C. W., and J. M. Bishop, 1977: An example of Gulf Stream eddy-induced water exchange in the Mid-Atlantic Bight. J. Phys. Oceanogr., 7, 474-479.

Naiyou, X., X. Qichun, and M. Tiansong, 1992: Relationship between the subtropical high in summer and the thermal regime anomaly in the northwest Pacific. J. Ocean Univ. Qingdao, 22, 29-38.

Paden, C. A., M. R. Abbott, and C. D. Winant, 1991: Tidal and atmospheric forcing of the upper ocean in the Gulf of California. 1. Sea surface temperature variability. J. Geophys. Res., 96, 18 337-18 359

Panitz, H. J., and P. Speth, 1986: The influence of the surface wind stress over the equatorial Atlantic on oceanic upwelling processes during FGGE 1979. Oceanogr. Trop., 21, 185-203.

Sirovich, L., 1987a: Turbulence and the dynamics of coherent structures. Part I: Coherent structures. Quart. Appl. Math., XLV, 561571.

— 1987b: Turbulence and the dynamics of coherent structures. Part II: Symmetries and transformations. Quart. Appl. Math., XLV, 573-583.

- 1987c: Turbulence and the dynamics of coherent structures. Part III: Dynamics and scaling. Quart. Appl. Math., XLV, 584590.

, 1991: Empirical eigenfunctions and low dimensional systems. New Perspectives in Turbulence, L. Sirovich, Ed., Springer, 139163.

- , and R. Everson, 1992: Analysis and management of large scientific databases. Int. J. Supercomputing Applic., 6, 50-68.

Stewart, G., 1993: On the early history of the singular value decomposition. SIAM Rev., 35, 551-566.

Stommel, H., 1966: The Gulf Stream. University of California Press, $248 \mathrm{pp}$.

Tanimoto, Y., N. Iwasaka, K. Hanawa, and Y. Toba, 1993: Characteristics of sea surface temperature with multiple time scales in the North Pacific. J. Climate, 6, 1153-1160.

Thompson, K. R., T. H. Loucks, and R. W. Trites, 1988: Sea surface temperature variability in the shelf-slope region of the northwest Atlantic. Atmos.-Ocean, 26, 282-299.

Voorhis, A. D., D. C. Webb, and R. C. Millard, 1976: Current structure and mixing in the shelf/slope water front south of New England. J. Geophys. Res., 81, 3695-3708.

Weare, B. C., 1977: Empirical orthogonal analysis of Atlantic Ocean surface temperatures. Quart. J. Roy. Meteor. Soc., 103, 467478.

Wright, W. R., and C. E. Parker, 1976: A volumetric temperature/ salinity census for the Middle Atlantic Bight. Limnol. Oceanogr., 21, 563-571.

Zheng, Q., V. Klemas, and N. E. Huang, 1984: Dynamics of the slope water off the New England and its influence on the Gulf Stream inferred from satellite IR data. Remote Sens. Environ., 15, 135153. 